\title{
Population Growth and Life Expectancy in Nigeria: Issues and Further Considerations
}

Oladayo Timothy POPOOLA ${ }^{1}$

${ }^{1}$ Department of Economics, Ahmadu Bello University, Zaria, Nigeria

Correspondence: Popoola, Oladayo Timothy, Department of Economics, Ahmadu Bello University, Zaria, Nigeria. Tel: 234(0)813-574-5100. E-mail: poladayo@gmail.com

Received: April 25, 2018; Accepted: May 15, 2018; Published: May 19, 2018

\begin{abstract}
This study empirically investigates the effects of population growth on average life expectancy in Nigeria taking into account the explicit role of healthy citizens in economic development as well as other control variables not considered in prior studies. Predicted on country-specific regression and Granger Causality test using time series data between 1986 and 2015, the findings reveal that rising population growth have positive and insignificantly impacts life expectancy; but $1 \%$ decrease in fertility rate and population of 65 -and-above dependency ratio could positively stimulates an improvement in longevity by 5.84 , and 81.5 respectively in Nigeria. Furthermore, the granger causality test shows that population growth could granger cause low life expectancy in Nigeria at least at $10 \%$ level of significant. The findings therefore make a case for strengthening efforts towards reducing both fertility rate and age 65 and above dependency ratio with priority given to the welfare of ages 65 and above population in Nigeria.
\end{abstract}

Keywords: Population Growth, Health and Development, Nigeria, Granger Causality, Regression

JEL Classification: J11, I15, C13

\section{Introduction}

Is rapid population growth good or bad for longevity? Both theories and empirical studies are yet to provide satisfying explanation about the implications of rising population growth on average life expectancy even in developed countries. Specifically, some theories suggest that more increasing population growth could be bad for health status of citizens and their life expectancy because with a larger population there would be more pressure on health facilities especially in developing countries. While others explain that rising population growth could lead to greater productivity either by inducing innovation, producing innovation or through creating greater economies of scale even in medical-care services (Turner, 2014; and Mateo, 2016).

In recent years, growing population has become a key issue of concern to Nigerian and policy makers alike. This is because, rising population in terms of its composition and size, has far-reaching implication for citizens' quality of life. As Odusina (2011) observes, population is a major asset of the developing countries, as resource for economic growth and development, and is also the prime beneficiary of development. It often constitutes the bulk of the producers of goods and services as well as the major consumers of the goods and services. However, the impact of population on development depends not only on the absolute size but also on its quality and implications. Obviously, Nigeria's population is large with appropriately 194 million people (United Nations, 2017). Her population is also about $3 \%$ of the world population with a population growth rate of about $2.62 \%$ annually alongside with low GDP growth rate of $-1.54 \%$ (during economic recession) respectively in 2016 (World Bank, 2017). This implies that the current population growth rate in Nigeria exceed the GDP growth rate. With rising population, it become increasingly important to also increase health financing and infrastructure; however, the total health financing (percentage of GDP) is $3.67 \%$ in 2016 which is low compare to health spending (\% of GDP) of $4.32 \%$ and $4.47 \%$ in 2004 and 2007 respectively (World Bank, 2017).

Consequently, the average life expectancy at birth in Nigeria is merely 53 years in recent years, while it is above 80 years for countries like France, Japan, Singapore, and Hong Kong. For Ghana and Niger, their average life expectancies were 64 and 61 years respectively in 2015 (World Bank, 2017). All these perhaps explain why Nigeria was far from reaching the health-related targets of the recent past Millennium Development Goals (Novignon et al., 2015; WHO, 2015). Another worrisome issue is the high prevalence of; malaria, cholera, acute hepatitis E, stroke, hypertension, typhoid, and all forms of cancer that often constraint longevity (WHO, 2017). Evidence from 
prior studies have also shown that life expectancy at birth is low in Nigeria (see Novignon et al., 2015; World Bank, 2017; Karimo et al., 2017).

The foregoing suggests that probably insufficient health facilities to meet the population needs, in addition to inadequate health financing and infrastructure resulted from poor governance might be accounting for low life expectancy in Nigeria. Although the impact of population growth towards education, urbanization, public finance and economic growth has been established (see Mateo, 2016; Bussolo et al. 2015; and Bloom et al., 2011), its longevity-impact has not received adequate attention from previous studies. Therefore, this paper relies on the country-specific regression to comparatively ascertain the effects of population growth, infrastructure and health financing on life expectancy in Nigeria. This is with a view to proffer sustainable strategies for health sector development in Nigeria. Following this introductory section, review of related literature is presented in section two. Section three present methodology while section four focus on findings. Finally, section five concludes and draws lessons for Nigeria.

\section{Review of Related Literature}

Population growth rate is an increase in the number of people that reside in a country, state, or city over time. The global population rise from 2.5 billion to 5.7 billion people between 1950 and 1995, and presently the statistics is nearly 7.6 billion in 2017 up from 7.4 billion in 2015; the figure is also expected to grow to 9.8 billion people by 2050 (United Nations, 2017). As the report noted, despite nearly universal lower fertility rates globally, the increase is still spurred by the relatively high levels of fertility in developing countries. For Nigeria, the report of United Nations' World Population Reviews (2018) further indicate that among the ten largest countries globally, Nigeria is growing the most rapidly. Specifically, as of 2018 the estimated population of the country is 195.88 million (United Nations, 2018). As Figure 1 indicate, the population growth of Nigeria has been on the rising since 1997 from $2.48 \%$ to $2.69 \%$ in 2015 (World Bank, 2017).

\section{Population growth rates}

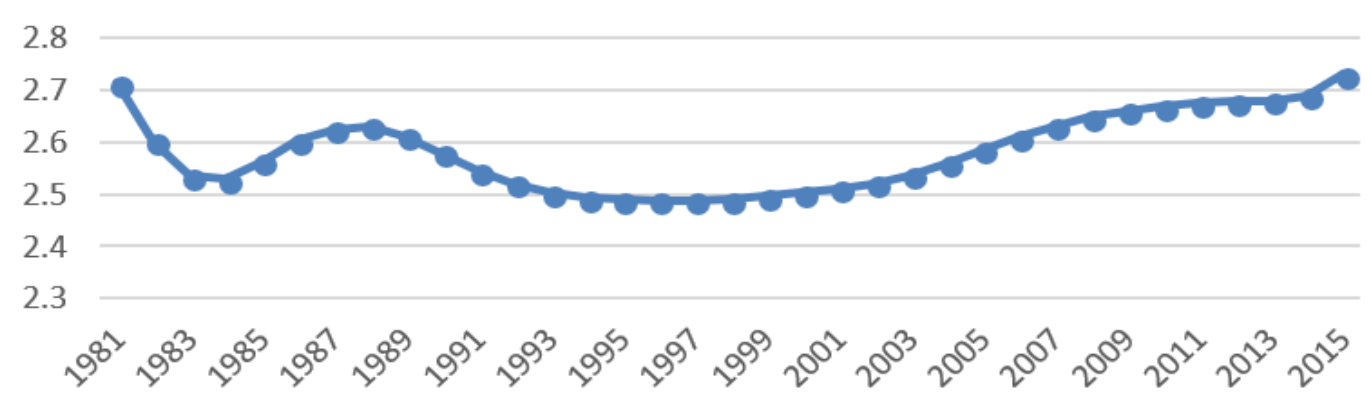

Figure 1. Population Growth Rates in Nigeria (1981 - 2015)

Source: World Bank Development Indicator (2017)

Figure 2 indicate that in recent years the percentage of 0 to 14 years old population to the total population in Nigeria is about $44 \%$ in 2016.

\section{Population ages 0-14 (\% of total)}

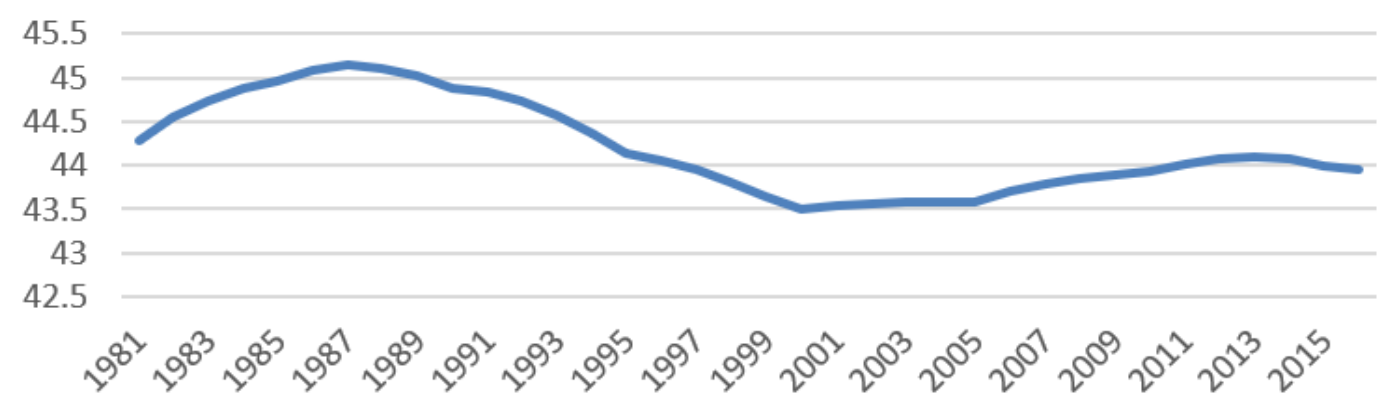

Figure 2. Percentage of Population ages 0-14 to Total in Nigeria (1981 - 2016)

Source: World Bank Development Indicator (2017) 
While Figure 3 show that the percentage of 15 to 64 years old as been rising over time in Nigeria. The population of ages 15-64 years to the total population in Nigeria increase from 51\% in 1986 to 53\% in 2016 (see World Bank, 2017).

\section{Population ages 15-64 (\% of total)}

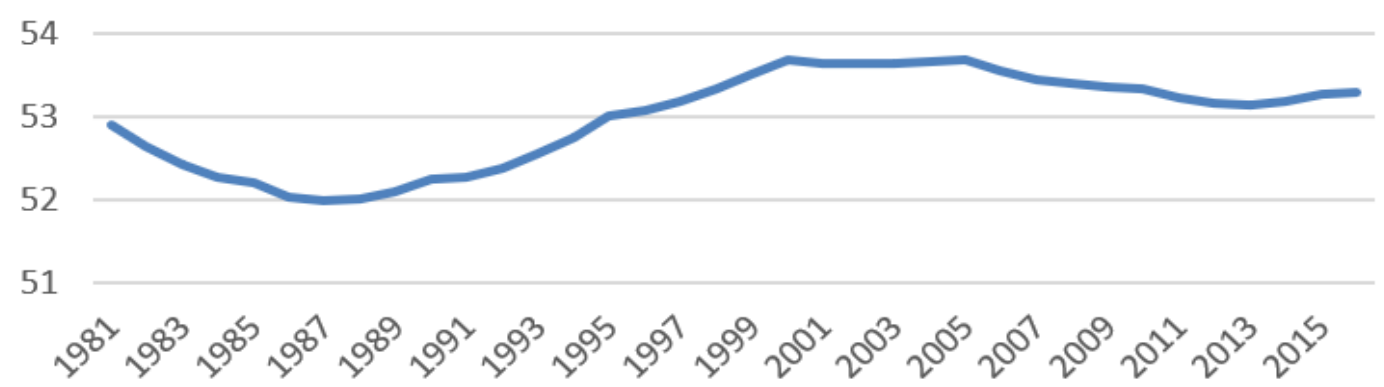

Figure 3. Percentage of Population ages 15-64 to Total in Nigeria (1981 - 2016)

Source: World Bank Development Indicator (2017)

Conversely, the population of Nigerian from ages 65 years and above to percentage of the total population declines over decades. For instance, in 1986 the figure was about $2.9 \%$, while in 2016 the statistics reduce to $2.74 \%$ to total population as Figure 4 revealed. This imply that longevity in Nigeria is decreasing.

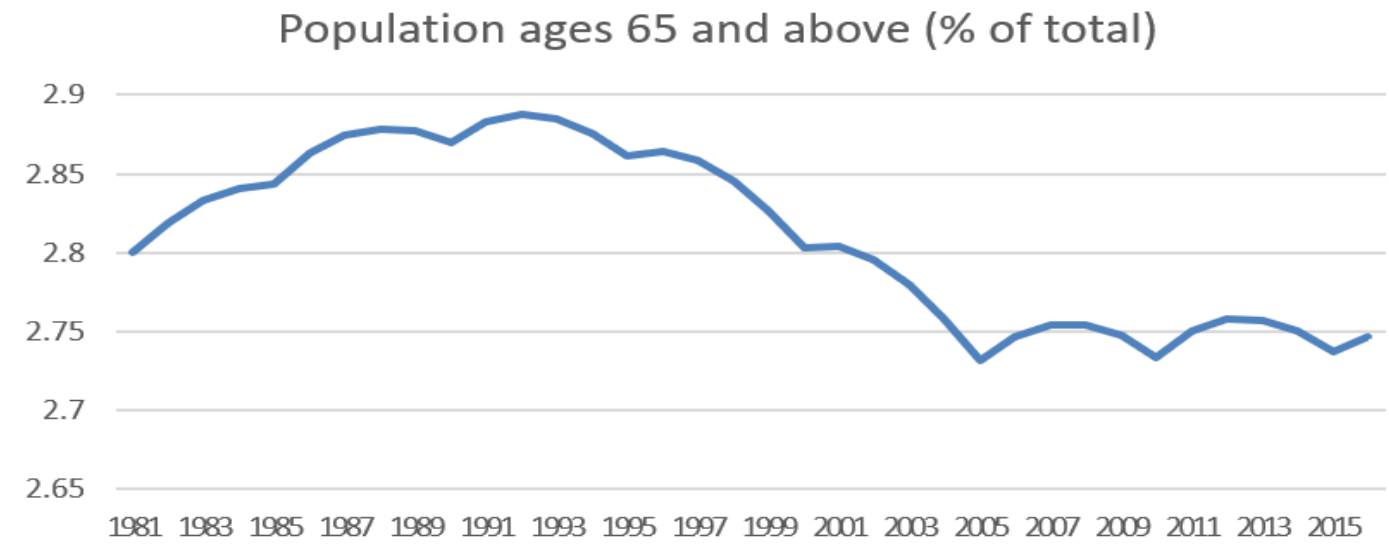

Figure 3. Percentage of Population ages 65 and above to Total in Nigeria $(1981-2016)$

Source: World Bank Development Indicator (2017)

For longevity or life expectancy (LEB), which refers to the average number of years an infant is expected to live if mortality patterns at the time of birth remains constant in the future (World Bank, 2016). It is the average-period that a person is expected to live as determined taking account of current economic situation. This also reflects the overall mortality level of a population, and summarizes the mortality pattern that prevails across all age groups (WHO, 2006). It also indicates the number of years an infant would live provided the patterns of mortality continues at the time of birth were to stay the same throughout his life. Hence, it is an important index of long life and quality of living (Grepin and Bharadwaj, 2015). Table 1 reveals that LEB in Nigeria increased marginally from 46 years in 1995 to about 53 years in 2015, while Rwanda's LEB increased from 31 years to about 65 years during the same period (World Bank, 2017). In comparison, LEB in Nigeria is lower compared with Ghana and South Africa. 
Table 1. Average Life Expectancy at birth (total) in Nigeria compare to other countries

\begin{tabular}{lllllllll}
\hline & $\mathbf{1 9 8 0}$ & $\mathbf{1 9 8 5}$ & $\mathbf{1 9 9 0}$ & $\mathbf{1 9 9 5}$ & $\mathbf{2 0 0 0}$ & $\mathbf{2 0 0 5}$ & $\mathbf{2 0 1 0}$ & $\mathbf{2 0 1 5}$ \\
\hline Cote d'Ivoire & 50.7 & 52.6 & 52.6 & 49.5 & 46.7 & 47.7 & 50.1 & 51.9 \\
Ghana & 52.3 & 54.1 & 56.7 & 57.5 & 56.9 & 58.7 & 60.6 & 63 \\
South Africa & 56.9 & 59.9 & 62.1 & 61.4 & 55.8 & 51.5 & 54.4 & 57.4 \\
Rwanda & 47.9 & 50.4 & 33.4 & 31.6 & 48.1 & 54.7 & 61.4 & 64.5 \\
Nigeria & 45.5 & 46.3 & 46.1 & 46.1 & 46.6 & 48.6 & 51.3 & 53.0 \\
\hline
\end{tabular}

Source: Compiled from World Development Indicator, 2017

Theoretically, the debate over population growth and its significance for human welfare and their longevity was raised in Robert Malthus studies on population, in the sense that growth of population depends upon the means of subsistence, primarily the food supply (Thompson, 2010). Malthusian explanation predicts a fast and steady population growth for countries with an abundance of natural resources until the points where abundance turns to scarcity since the production growth would be linear and population growth exponential (Bussolo et al. 2015, and Thompson, 2010). With time, the exponential function would return the linear production function and lead to famine or other disasters. Other economists like Adam Smith (1937), Schumpeter (1954), and Rostow (1990) further provided insight about the relationship between population growth and subsistence resources.

These theories led to various empirical findings. For instance, Istaiteyeh (2017) investigate the impact of socioeconomic determinants (including per capita GDP, public spending on health, urban population, and secondary school enrolment) on life expectancy in Jordan. The study covers the period from 1990 to 2014 and employed Vector Auto-Regression technique (VAR). The empirical findings indicate that unemployment and secondary school enrolment explains longevity in Jordan. In Nigeria, Ilori et al. (2017) examines an empirical evidence of the specific impact of public health expenditure on life expectancy in Nigeria using time series data spanning between 1981 and 2014. Their study employ bounds testing co-integration and Autoregressive Distributed Lag (ARDL) procedures to determine the relationship between public spending on health and life expectancy in Nigeria. The results indicate that School Enrolment and carbon-dioxide emission significantly and directly influenced life expectancy in Nigeria, while School Enrolment was found to be insignificant in both short and long runs contrary to economic theory.

Ratna and Sari (2016) examine empirically the relationship between the health budget, human capital and population growth in Indonesia by using both quantitative and qualitative analysis. Their quantitative results from regression technique support the theory that there is significant no relationship between life expectancy and population growth, while their qualitative analysis is used to describe the role of formal and informal institutions, including financial institutions in reducing birth rates in an effort to improve human capital. However, Shahbaz et al. (2016) focused on life expectancy drivers in Pakistan. Their findings conclude that rural-urban inequality in income and economic misery have substantial inverse impact on life expectancy, but urbanization support life expectancy, while illiteracy declines it.

The study of Hansen and Lonstrup (2013) indicates that increase in longevity decreased per capita GDP growth and rising population growth. These findings are robust to the inclusion of initial life expectancy and initial GDP per capita. Currais (2000) take into account the extent to which fertility and mortality affect the population growth rate. His findings indicate that mortality depends on health expenditure and fertility rate, and that household often take into account the welfare and resources of their current and future that concerns population growth rate. In sum, most of the empirical studies conducted especially in developed and developing countries including Nigeria with emphasis on public health spending, per capita GDP, rural-urban inequality in income, and unemployment on life expectancy. However, these studies failed to appropriately account for the impact of population growth on longevity and the effect of fertility rate and age 65 and above dependency ratio. Hence, this study will bridge the gap in the empirical literature by investigating the impact of population growth on life expectancy in Nigeria.

\subsection{Theoretical Framework}

Grossman (1972) theorized that health status (H) is determined by various factors (X). This implies that:

$$
\boldsymbol{H}=\boldsymbol{f}(\boldsymbol{X})
$$

where $\mathrm{X}$ are population growth ratio (PG), age 65 and above dependency ratio as percentage of working-age (AD), fertility rate (FR), and population ages 65 and above as the percentage of the total population (PA) in Nigeria.

Thus, 


$$
\mathrm{LE}=\mathrm{f}(\mathrm{PG}, \mathrm{AD}, \mathrm{FR}, \mathrm{PA})
$$

From the foregoing, the model utilized for this study is in the spirit of Istaiteyeh (2017). However, the model differs in that it considers the impacts of population growth rate, age 65 and above dependency ratio as percentage of working-age, fertility rate, and population ages 65 and above as the percentage of the total population in Nigeria. From equation (2), the econometric model is specified as:

$$
L E_{t}=\alpha+\beta_{1} P G_{t}+\beta_{2} A D_{t}+\beta_{3} F R_{t}+\beta_{3} P A_{t}+\mu
$$

where $\boldsymbol{\mu}$ is the error term assumed to satisfy the Gaussian white noise condition. Apriori, the ADW, FRT and PA are expected to exert inverse influence on longevity or average life expectancy (LE), while PG could either be positive or negative.

\subsection{Scope and Data Sources}

The study employs annual data spanning 1981 to 2016. The description and definitions of variables, including the sources are given in Table 2.

Table 2. Descriptive Statistics of Variables in Nigeria

\begin{tabular}{lll}
\hline Variable & Descriptions & Sources \\
\hline LE & Longevity or average life expectancy at birth & World Bank Development Indicators (WDI, 2017) \\
PG & $\begin{array}{l}\text { Population Growth Rate } \\
\text { Age 65 and above dependency ratio as } 2017\end{array}$ & WDI, 2017 \\
AD & $\begin{array}{ll}\text { percentage of working-age } \\
\text { WDI, 2017 }\end{array}$ \\
FR & $\begin{array}{l}\text { Fertility Rate } \\
\text { PA } \\
\text { population ages 65 and above as the }\end{array}$ & WDI, 2017 \\
\hline
\end{tabular}

Source: Author Compilation, 2018

\section{Empirical Analysis}

\subsection{Descriptive Statistics}

The descriptive statistics of variables used in the estimations is presented in Table 3. From the table, the average LE is 48 years old with standard deviation of 2.57 years. The minimum population growth was 2.49 percent, while the average fertility rates is 6 children per woman in Nigeria for the periods under study. Again, the correlation matrix table presented in Table 4 reveal that, high inverse correlation exists among all the variables and LE except PG. For instance, the correlation between LE and FR is about 86 percent.

Table 3. Descriptive Statistics of Variables in Nigeria

\begin{tabular}{llllll}
\hline Variables & LE & PG & AD & FR & PA \\
\hline Mean & 48.06 & 2.58 & 5.31 & 6.19 & 2.81 \\
Standard Deviation & 2.57 & 0.07 & 0.15 & 0.37 & 0.05 \\
Maximum & 54 & 2.49 & 5.09 & 5.52 & 2.73 \\
Minimum & 45.85 & 2.72 & 5.54 & 6.78 & 2.89 \\
Observations & 36 & 36 & 36 & 36 & 36 \\
\hline
\end{tabular}

Source: Own Computations with Stata 13

Table 4. Correlation Matrix (1981-2016)

\begin{tabular}{cccccc}
\hline & LE & PG & AD & FR & PA \\
\hline LE & 1.00 & & & & \\
PG & 0.65 & 1.00 & & & \\
AD & -0.75 & -0.39 & 1.00 & & \\
FR & -0.86 & -0.28 & 0.81 & 1.00 & \\
PA & -0.83 & -0.57 & 0.97 & 0.77 & 1.00 \\
\hline
\end{tabular}

Source: Own Computations with Stata 13 


\subsection{Unit Root Test}

The study tests for unit roots for all the variables. Augmented Dickey-Fuller (ADF) and Phillip-Perron (PP) are used to perform the tests. The results of the stationarity tests of variables at levels are presented in Table 5 .

Table 5. Results of Unit Root Tests (1981-2016)

\begin{tabular}{lllllllll}
\hline Variables & $\begin{array}{l}\text { ADF test } \\
\text { at level }\end{array}$ & $\begin{array}{l}\mathbf{9 0 \%} \\
\text { Critical }\end{array}$ & $\begin{array}{c}\text { ADF } \\
\text { level }\end{array}$ & $\begin{array}{l}\text { Order } \\
\text { Integration }\end{array}$ & of & $\begin{array}{l}\text { PP test at } \\
\text { level }\end{array}$ & $\begin{array}{l}\mathbf{9 0 \%} \\
\text { critical level }\end{array}$ & $\begin{array}{l}\text { Order } \\
\text { Integration }\end{array}$ \\
\hline LE & 5.993 & -2.618 & & $\mathrm{I}(0)$ & 2.547 & -10.40 & $\mathrm{I}(1)$ \\
PG & -2.027 & -2.618 & & $\mathrm{I}(1)$ & -4.820 & -10.40 & $\mathrm{I}(1)$ \\
AD & -0.234 & -2.618 & & $\mathrm{I}(1)$ & -0.315 & -10.40 & $\mathrm{I}(1)$ \\
FR & -2.041 & -2.618 & $\mathrm{I}(1)$ & -0.116 & -10.40 & $\mathrm{I}(1)$ \\
PA & -0.153 & -2.618 & $\mathrm{I}(1)$ & -2.945 & -10.40 & $\mathrm{I}(1)$ \\
\hline
\end{tabular}

Source: Own Computations with Stata 13

The findings in Table 5 indicate that all the variables except LE are non-stationary at levels for ADF. The unit root tests applied to the variables at levels reject the null hypothesis of stationarity with evidence from PP test for all the variables. The variables are therefore, differenced once and they are confirmed to be stationary. The ADF and PP tests applied to the first difference of the data series accept the null hypothesis of stationarity for all the variables. Thus, the variables are integrated of order one I (1).

\subsection{Co-integration Test}

Considering the unit root tests of the variables, the study proceeded to establish whether or not there is a long-run co-integrating nexus among the variables (LE, PG, AD, FR, and PA) by using the Johnasen full information maximum likelihood method. The Johnasen tests (as presented in Table 6) indicated that the trace and maximal eigenvalue statistics revealed the existence of four co-integrating relationships between LE and other variables at the 5 percent level of significance. The conclusion drawn from this result is that there exists a unique long-run relationship between $\mathrm{LE}, \mathrm{PG}, \mathrm{AD}, \mathrm{FR}$, and PA.

Table 7. Johnasen Co-Integration Test Results

\begin{tabular}{ccccc}
\hline Hypothesized & Eigenvalue & Trace Statistic & 5\% Critical value & Prob. \\
\hline None* & 0.97 & 200.7 & 69.8 & 0.0000 \\
At most $1^{*}$ & 0.74 & 86.1 & 47.9 & 0.0000 \\
At most $2 *$ & 0.54 & 40 & 29.8 & 0.0024 \\
At most 3 & 0.25 & 13.9 & 15.5 & 0.0857 \\
At most $4 *$ & 0.118 & 4.27 & 3.8 & 0.0384 \\
\hline
\end{tabular}

Source: Own Computations with Stata 13

The long-run longevity (LE) can be obtained by normalizing the estimates of the unconstrained co-integrating vector for the long-run $\mathrm{LE}$ are presented in equation 4.

Table 8. Normalized Co-integration Coefficients

\begin{tabular}{lllll}
\hline LE & PG & AD & FR & PA \\
\hline 1.0000 & -79.98 & 107.06 & -5.79 & -268.74 \\
& $(3.22)$ & $(9.96)$ & $(1.78)$ & $(21.96)$ \\
\hline
\end{tabular}

Source: Own Computations with Stata 13

$$
\mathrm{LE}=-79.98 \mathrm{PG}+107.06 \mathrm{AD}-5.79 \mathrm{FR}-268.74 \mathrm{PA}
$$

\subsection{Dynamic Specification of Longevity}

In the short-run, deviations from this relationship could occur due to changes to any of the variables (PG, AD, FR, and PA). Due to the differences between dynamics governing the short-run and long-run behaviour, the short-run 
interactions and the adjustments to long-run equilibrium are paramount because of the policy implications. The Error-Correction Model (ECM) is expected to be negatively signed and significant in the LE function. This result as presented in Table 9 substantiates the finding of co-integration among the variables reported earlier. Table 9 also indicate that the error-correction term of 18 percent, suggesting that the disequilibrium in the LE model is offset by annual short-run adjustment.

Table 9. Error Correction Model Test

\begin{tabular}{lllll}
\hline Variable & Coefficient & Standard Error & t-statistic & Probability \\
\hline ECT(-1) & -0.1756 & 0.1010 & -1.7391 & 0.0926 \\
\hline
\end{tabular}

Source: Own Computations

\subsection{Granger Causality}

LE and PG are inter-linked and co-related through various links. Although there seem to be no empirical or theoretical insight that could conclusively indicate sequencing from either direction. Therefore, the Granger Causality test for this study was carried out on LE and PG. The results (as presented in Table 10) indicates the existence of a bi-directional causality at 10 per cent level of significant which runs from LE to PG and vice versa at lag 2 .

Table 10. Granger Causality Test

\begin{tabular}{llllll}
\hline Null Hypothesis & Lag & Observation & F-Statistics & Prob. & Decision \\
\hline LE does not granger cause PG & 1 & 35 & 10.03 & 0.0034 & REJECT \\
& 2 & 34 & 5.31 & 0.0108 & REJECT \\
PG does not granger cause LE & 1 & 35 & 1.63 & 0.2104 & ACCEPT \\
& 2 & 34 & 2.99 & 0.0659 & REJECT \\
\hline
\end{tabular}

Source: Own Computations

\subsection{Regression Results}

The regression estimation results are reported in Table 11; although, rising population growth have positive and insignificantly impacts life expectancy in Nigeria, but FR and PA have negative and significant impacts on longevity in Nigeria. This means that 1 percent decrease in FR, AD, and PA could positively stimulates an improvement in life expectancy by $5.84,27.7$, and 81.5 respectively. These findings confirmed that of Ratna and Sari (2016) in Indonesia. Therefore, increase in any of these variables could trigger longevity in Nigeria. The $\mathrm{R}^{2}$ as shown in the result is 97.5 per cent, this value indicates that the model explains about 97.5 per cent of the behaviour of life expectancy in Nigeria. At 0.0000 , the probability value indicates that the regression estimation result is highly and statistically significant.

Table 11. Regression Results Table

\begin{tabular}{ccccc}
\hline Variables & Coefficient & Standard Deviation & t-statistics & Probability Value \\
\hline Constant & 162.302 & 16.031 & 10.12 & 0.0000 \\
PG & 1.643 & 2.131 & 0.770 & 0.4460 \\
FR & -5.846 & 2.131 & -17.06 & 0.0000 \\
AD & 27.678 & 3.235 & 8.55 & 0.000 \\
PA & -81.530 & 9.560 & 10.12 & 0.000 \\
\hline
\end{tabular}

Source: Own Computations with Stata 13

\section{Conclusion and Recommendations}

This study investigates the dynamics of population growth and life expectancy in Nigeria. The empirical results suggest a long-run relationship between population growth and longevity for a 35-years data period spanning 1981 to 2016. This result is consistent with Istaltayeh (2017) that investigated the impact of socio-economic determinants that includes per capita GDP, government expenditure on health, secondary school enrolment, and 
urban population on life expectancy in Jordan. Although, the regression estimated results of this study indicates that population growth is insignificant in predicting life-expectancy; however, it indicates that rising fertility rate and population of 65 and above dependency ratio would reduce life expectancy in Nigeria.

The implication of the findings is that rising population growth have positive and insignificantly impacts life expectancy; but $1 \%$ decrease in fertility rate and population of 65 -and-above dependency ratio could positively stimulates an improvement in longevity by 5.84 , and 81.5 respectively in Nigeria. Furthermore, the granger causality test shows that population growth could granger cause low life expectancy in Nigeria at least at $10 \%$ level of significant. These results therefore suggest that for policy makers in Nigeria to increase average life expectancy of her citizens, attention should be given to reducing fertility rate. More importantly, a higher level of attention should be given to timely payment of pensions and gratuity, this will reduce over dependency ratio in Nigeria. Also, policies aimed at improving the welfare of population ages 65 and above should be given more prominent attention.

\section{References}

Bloom, E. D., Canning, D., \& Fink, G. (2011). Implications of Population Ageing for Economic Growth. PGDA Working Paper, No 64

Bussolo, M., Koettl, J., \& Sinnott, E. (2015). Golden Ageing: Prospects for Healthy, Active and Prosperous Aging in Europe and Central Asia. Europe

Currais, L. (2000). Population, Growth and Health Expenditure. Department of Economic Analysis, Faculty of Economics, La Coruria University

Grepin, K. A., \& Bharadwaj, P. (2015). Maternal Education and Child Mortality in Zimbabwe. Journal of Health Economics, 44, 97-117. https://doi.org/10.1016/j.jhealeco.2015.08.003

Grossman, M. (1972). On the Concept of Health Capital and the Demand for Health. The Journal of Political Economy, 80(2), 223-255. https://doi.org/10.1086/259880

Hansen, C. W., \& Lonstrup, L. (2013). The Rise of Life Expectancy and Economic Growth in the 20 ${ }^{\text {th }}$ Century. Discussion Papers on Business and Economics, No 16. https://doi.org/10.2139/ssrn.2340926

Ilori, I. A., Olalere, S. S., \& Babatola, M. A. (2017). An Empirical Analysis of Public Health Expenditure on Life Expectancy: Evidence from Nigeria. British Journal of Economics, Management and Trade, 17(4), 117. https://doi.org/10.9734/BJEMT/2017/31783

Istaiteyeh, R. M. S. (2017). Economic and Social Factors in Shaping Jordan's Life Expectancy: Empirical Analysis (1990-2014). Advances in Management and Applied Economics, 7(5), 45-59.

Karimo, T. M., Krokeyi, W. S., \& Ekainsai, S. Z. (2017). Financial Burden Associated with ill-health: Evidence from the Elderly Population in Nigeria. Equatorial Journal of Social Sciences and Human Behaviour, 2(1), 25-43. https://doi.org/10.2139/ssrn.2925693

Mateo, Z. (2016). The Impact of Population Ageing on Public Finance in the Europe Union. University of Zagreb, Crotia.

Novignon, J., Nonvignon, J., \& Arthur, E. (2015). Health Status and Labour Force Participation in sub- Saharan Africa: A Dynamic Panel Data Analysis, African Development Review, 27(1), 14-26. https://doi.org/10.1111/1467-8268.12119

Odusina, E. K. (2011). Implications of Rapidly Growing Nigerian Population: A Reviews of Literature. Department of Demography and Social Statistics, Joseph Ayo Babalola University, Osun State, Nigeria.

Ratna, A. Z., \& Sari, L. Z. (2016). Health Budgets, Human Capital, and Population Growth: Empirical Study in Indonesia. Review of Integrative Business and Economics Research, 5(1), 357-368.

Shahbaz, M., Nanthakumar, L., Nooreen, M., Amjad, A., \& Ahmed, N. (2016). Determinants of Life Expectancy and its Prospects Under the Role of Economic misery: A Case of Pakistan. Social Indic Research, 126, 1299-1316. https://doi.org/10.1007/s11205-015-0927-4

Thompson, D. (2010). Is slow Population Growth good or bad for the Economy? The Atlantic, United States (U.S)

Turner, J. A. (2014). Are Ageing Populations Actually Good News? World Economic Forum

United Nation's World Population Reviews. (2018). Nigeria Population 2018. United Nations

United Nations. (2017). World Population Prospects: The 2017 Revision. United Nation Department of Economics and Social Affairs 
World Bank. (2017). World Development Indicators. Washington DC: World Bank

World Health Organization. (2015). Working Together for Health: The World Health Report

\section{Copyrights}

Copyright for this article is retained by the author(s), with first publication rights granted to the journal.

This is an open-access article distributed under the terms and conditions of the Creative Commons Attribution license (http://creativecommons.org/licenses/by/4.0/). 